Abstract paper to be presented at the Eighth Topical Meeting on the Technology of Fusion Energy, Salt Lake City, UT, October 9-13, 1988.

CONF-881031--40

DE89 003939

\title{
LIFETIME ANALYSIS OF THE ITER FIRST WALL AND DIVERTOR PLATES*
}

\author{
by \\ R. F. Mattas \\ Argonne National Laboratory \\ 9700 South Cass Ave. \\ Argonne, IL 60439
}

August 1988

\section{DISCLAIMER}

\begin{abstract}
This report was prepared as an account of work sponsored by an agency of the United States Government. Neither the United States Government nor any agency thereof, nor any of their employees, makes any warranty, express or implied, or assumes any legal liability or responsibility for the accuracy, completeness, or usefulness of any information, apparatus, product, or process disclosed, or represents that its use would not infringe privately owned rights. Reference herein to any specific commercial product, process, or service by trade name, trademark, manufacturer, or otherwise does not necessarily constitute or imply its endorsement, recommendation, or favoring by the United States Government or any agency thereof. The views and opinions of authors expressed herein do not necessarily state or reflect those of the United States Covernment or any agency thereof.
\end{abstract}

*Work supported by the U. S. Department of Energy, Office of Fusion Energy under Contract No. W-31-109-Eng-38. 
LIFETIME ANALYSIS OF THE ITER FIRST WALL AND DIVERTOR PLATES ${ }^{a}$

R.F. Mattas

Argonne National Laboratory

9700 South Cass Avenue

Argonne, IL 60439

(312) $972-8673$

\section{ABSTRACT}

The performance of the ITER first wall and divertor plate is analyzed using a 1-D lifetime code which includes the effects of radiation damage and surface erosion. The materials considered for the first wall are solution annealed and 20 \& cold-worked Type 316 stainless steel. The materials considered for the divertor plate are $\mathrm{H}-451$ graphite bonded to a $\mathrm{Cu}-0.5 \mathrm{Be}-2 \mathrm{Ni}$ heat sink. The primary conclusion is that it is crucial to include radiation effects for obtaining realistic predictions of performance.

\section{INTRODUCTION}

The ITER plasma facing components will be subjected to severe operating conditions which could limit the maximum allowable power density and useful lifetime of the machine. These components are simultaneously exposed to high Dlasma heat and particle fluxes as well as neutron radiation resulting in high thermal stresses, rapid surface erosion, and mechan1cal/physical property degradation. In order to assess the potential impact of the ITER operating environment on plasma facing i materials, a series of calculations have been performed which predict the temperature and stress distributions, along with the changes in materials properties within the ITER first wall and divertor plate.

The calculations were performed using the FLIP code, which is described in detall in Ref. 1. It is a $1-D$ code that is capable of analyzing plate structures which are either 1 completely constrained from bending and 1 expansion or are allowed to expand but not bend. For every time step, the crode first calculates the temperature distribution through the plate, followed by a calculation of the thermal strains. Finally, the stress distribution through the plate is determined. The temperatures, stresses, strains, and materials property behavior are then used

awork supported by the U.S. Department of Energy, Office of Fusion Energy.

\begin{abstract}
i
to evaluate the changes in the plate caused by the environment. The property changes evaluated by the program include mechanical strength and ductility, thermophysical properties, radiation creep and swelling, and fatigue and crack growth. The changes in properties and strains are used to recalculate the stresses within the plate, and the entire calculation process is repeated until the plate falls, or until the desired lifetime is achieved.
\end{abstract}

\section{MATERIALS CONSIDERATIONS}

The leading candidate materials for the first wall structure are either solution annealed or $20 \%$ cold-worked Type 316 stainless steel, and the leading candidate materials for tre divertor are copper alloys for the heat sink, and elther graphite or high-z macerials such as tungsten or tantalum for the plasma facing materials. In all cases, lowtemperature, low-pressure water is the coolant.

The equations used to represent the candidate materials are given in Ref. 1 and will not be repeated here. For metals, the thermophysical properties are a linear func$t$ ion of temperature, and they are assumed to be unaffected by neutron irradiation. The effects of neutron irradiation are included for the mechanical properties. Radiation hardening effects are particularly important in the case of solution annealed steel, where the initial strength is quite low. The differences in strength between annealed and cold-worked steel are illustrated in Fig. 1. The information used to predict radiation hardening in cold-worked steel includes the effects of both neutrons and helium generation, ${ }^{2}$ whereas, only neutron effects are considered for solution annealed material. 3

Graphite is unique in its response to radiation in that thermophysical properties will be significantly affected by radiation, and densification rather than swelling will occur. For the cases considered here, the -properties of $\mathrm{H}-451$ nuclear graphite are 


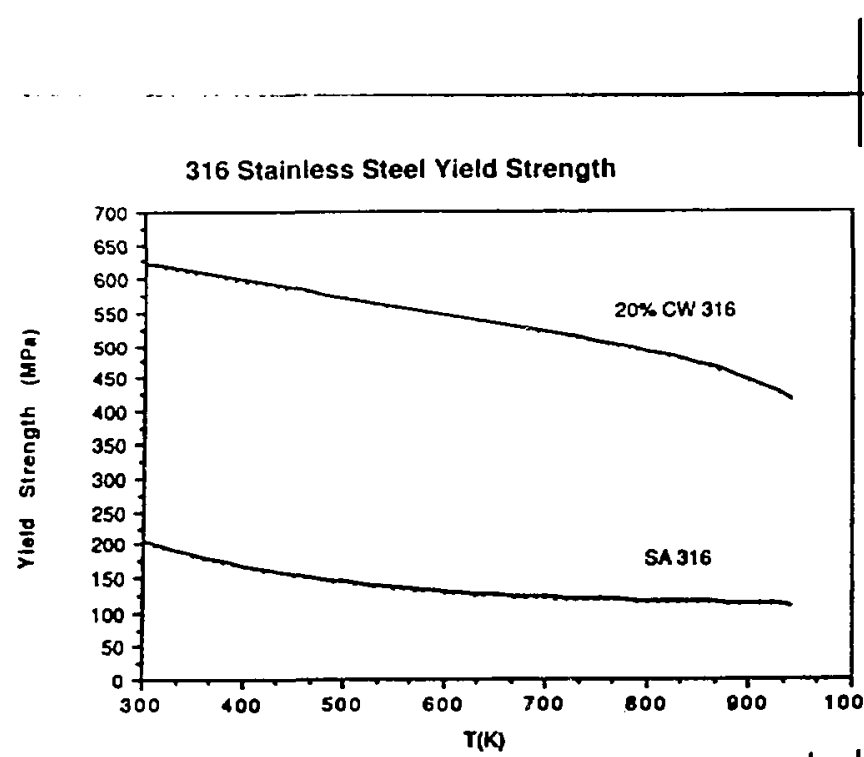

F: $:$. 1. Yield stress comparison for solution annealed and 20\% cold-worked Type 316 stainless steel.

used. ${ }^{4-8}$ As an example of the effect of neutron damage, the predicted and measured changes in thermal conductivity of $\mathrm{H}-451$ graphite are shown in Fig. 2. Most of the degradation of thermal conductivity takes place at a fluence of $<1 \mathrm{dpa}$. The predicted and measured changes in swelling for H-451 graphite are illustrated in $F i_{B}$. 3. At the temperatures of interest, the maximum densif 1 cation will be 5-9\% at fluences of 10-15 dpa. Other properties that are modeled include fracture strength and ductility, Young's modulus, thermal expansion, and radiation creep.

Finally, $\mathrm{Cu}-0.5 \mathrm{Be}-2 \mathrm{Ni}$ is used as the heat sink material. The tensile and thermophysical properties are largely taken from Ref. 9. Since radiation effects data are limited for this material, they are not taken into account except for radiation creep, which is assumed to be the same as Type 316 stainless steel.

It should be noted that in most cases tine effects of fusion radiation on candidate materials are not well known. Even in the case of Type 316 stainless steel, which has been extensively studied as part of the breeder reactor program, there are gaps in the data base. The great majority of data is at reactor relevant temperatures $\left(350-650^{\circ} \mathrm{C}\right)$, whereas the ITER first wall will operate at low temperatures $\left(<300^{\circ} \mathrm{C}\right)$. Another factor is the difference in helium generation rates between fission and fusion neutron spectrums. Cenerally, helium production is much higher in a fusion system, and additional helium could significantly affect irradiation response. For other materials, the data base is sparser than for stainless steel, and in some cases, irradiation behavior must be estimated from the data of similar materials
3: (e.g. similar crystal structure or compesition).

\section{FIRST WALL PERFORMANCE}

The portion of the rirst wall analyzed is the layer that is bonded to the coolant channels and directly exposed to the plasma, as - shown in Fig. 4. Because of the constraint imposed by the coolant channel ribs and the underlying support structure, the top plate is assumed to be totally constrained from both - bending and expansion. This constraint is - belleved to be conservative, since some - expansion and bending is likely to occur in 7 the actual first wall. The input conditions I for the calculations are shown in Table 1. The plate thickness is assumed to be $3 \mathrm{~mm}$, and two power densities were analyzed. Only the results at $0.4 \mathrm{~mW} / \mathrm{m}^{2}$ surface heat flux are i described here, but the results are qualitatively similar for a heat flux of $0.2 \mathrm{~mW} / \mathrm{m}^{2}$.

I

The temperature distribution through the first wall is shown in Fig. 5. At $0.4 \mathrm{~mW} / \mathrm{m}^{2}$ I surface heat flux, $\Delta T-80 \mathrm{~K}$. Because of the I difference in tensile strength between coldworked and annealed steel, the predicted stress distributions are considerably different, as shown in Fig. 6. The arnealed I material yield stress is exceeded at the I plasma side surface during the burn and dwell periods.

1

The effect of radiation is to increase the tensile strength and to alter the stress i distribution due to radiation creep. The preI dicted change in yield strength is illustrated in Fig. 7 which shows that annealed and coldworked material will eventually reach equivalent strength levels. The effect of stress i relaxation is to bring the stress level during I the burn to zero, while increasing the stress during the dwell period, as shown in Fig. 8 . The stresses are predicted to fully relax i during the burn after $-35,000$ cycles $(-0.22$ I years of full power operation). In the case I of annealed steel, the stress cycle becomes fully elastic after only -5000 cycles.

I

Fatigue damage accumulation for coldi worked steel is shown in Fig. 9. (Failure is I assumed to occur when the fatigue damage ( reaches unity.) Initially, when the stress cycle is all compressive, the rate of damage accumulation is low. With stress relaxation, the cycle becomes more tensile, and the I fatigue damage rate increases. In this case, 1 a surface fatigue crack is predicted to initiate after $-150,000$ cycles. Note that the ASME safety factors of two in strain range or 20 in cycles to failure is incorporated into 1 the calculations. Even with fatigue crack initiation, the first wall cannot be conI sidered to reach a failure condition. Crack growth from the fatigue crack must be analyzed to determine if it will propagate to failure. 


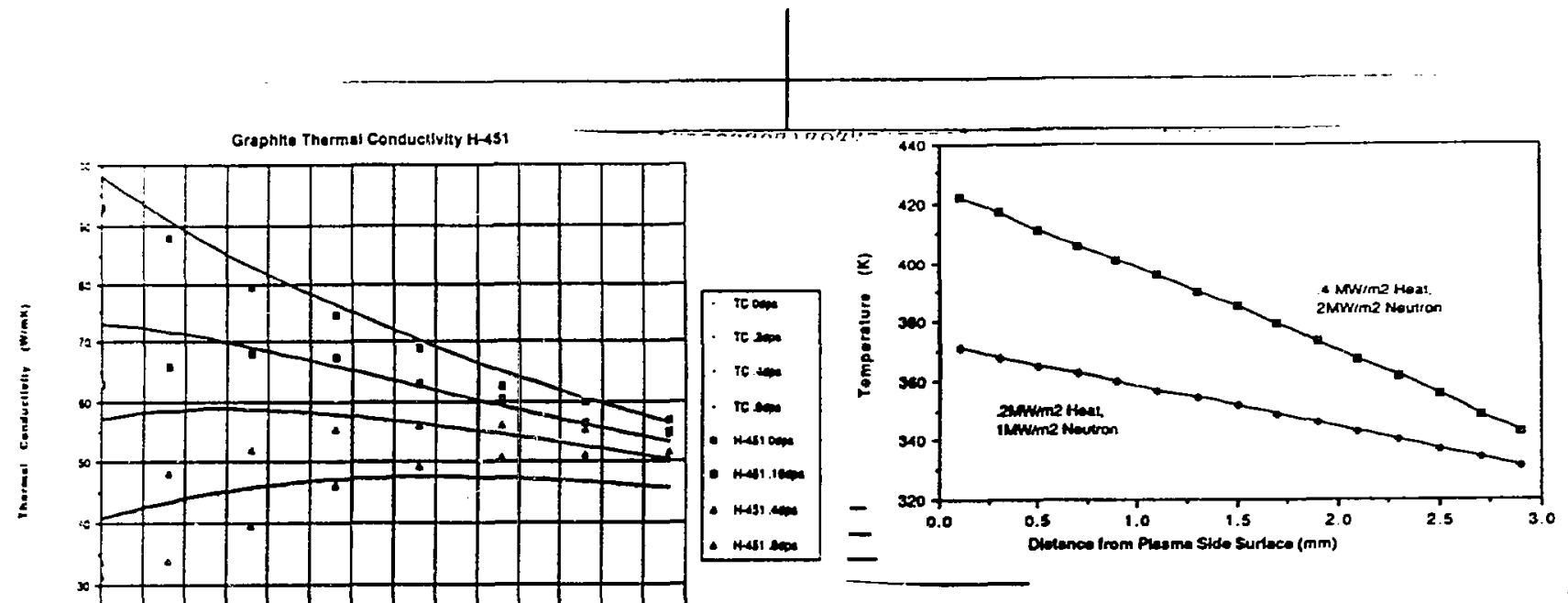

Fig. 5. Temperature distribution througn ITER FW.

mon

Fig. 2. Effect of radiation on thermal conductivity of $\mathrm{H}-459$ graphite.
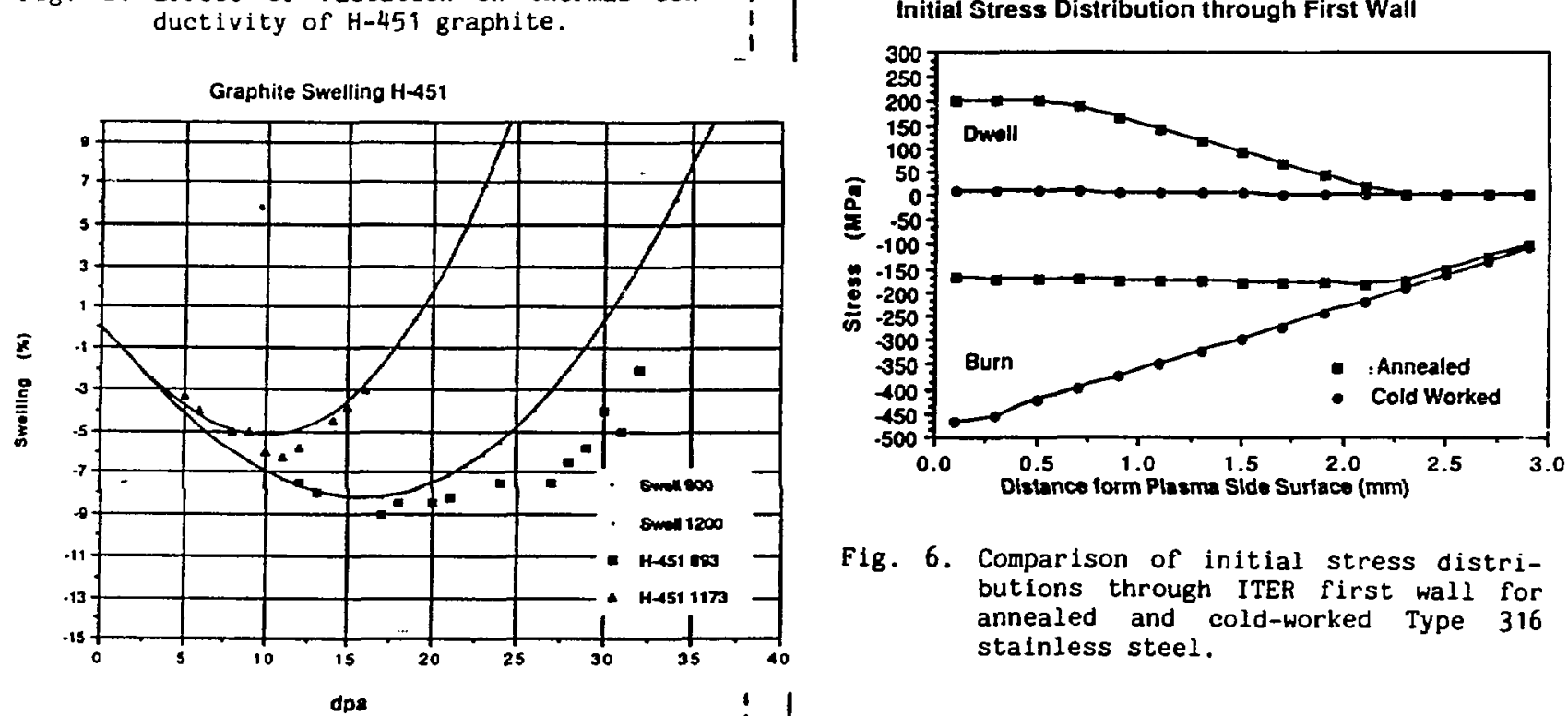

Fig. 6. Comparison of initial stress distributions through ITER first wall for annealed and cold-worked Type 316 stainless steel.

Fig. 3. Swelling response of $\mathrm{H}-451$ graphite.

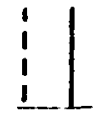

PLASMA

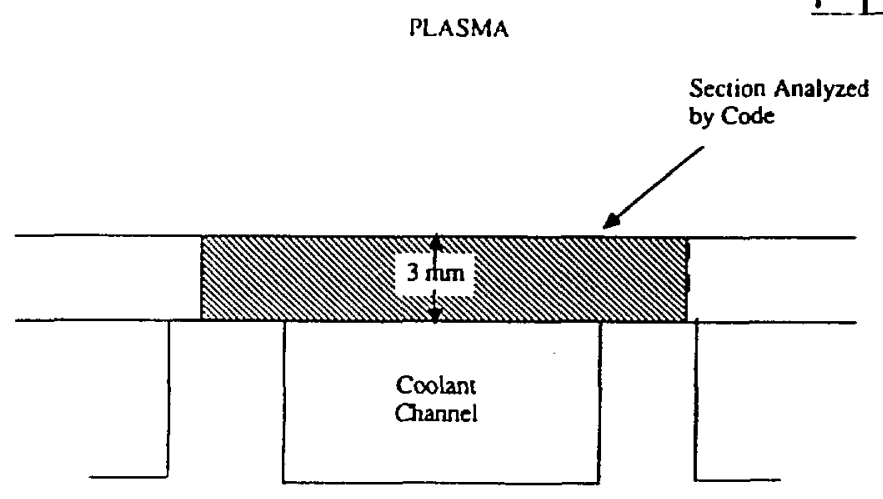

First Wall

Rib and Suppon Structure

Fig. 4. First wall section analyzed by FLIP code.

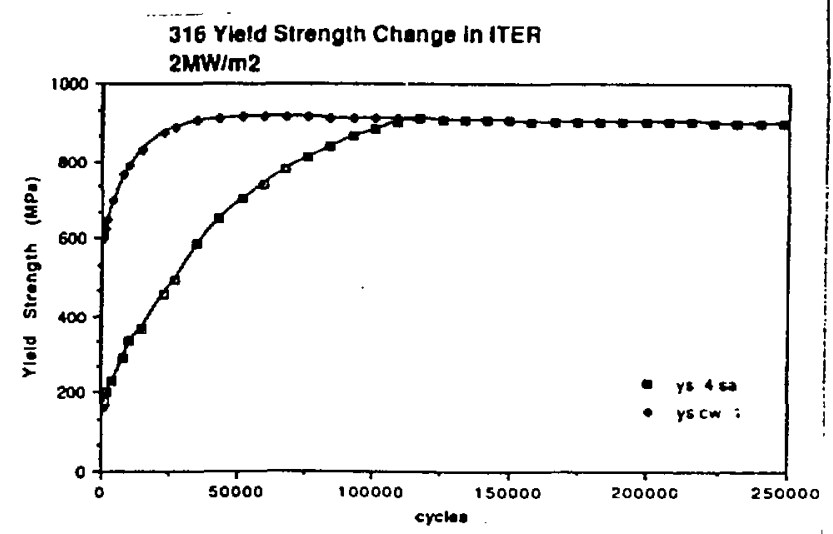

Fig. 7. Predicted change in yield strength with neutron irradiation of annealed and cold-worked Type 316 stainless steel. 



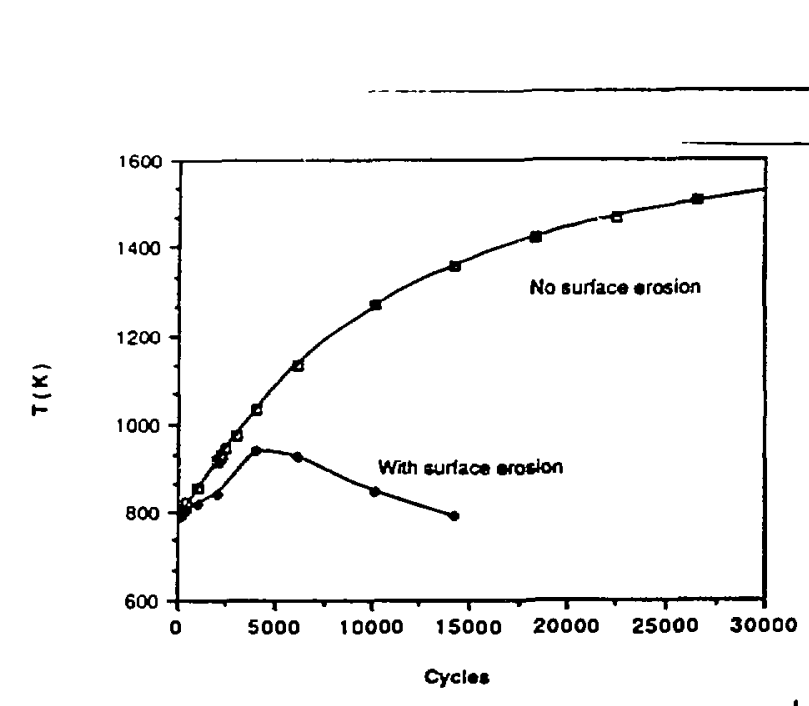

Fig. 10. Effect of irradiation and erosion on surface temperature of ITER graphite divertor plate.

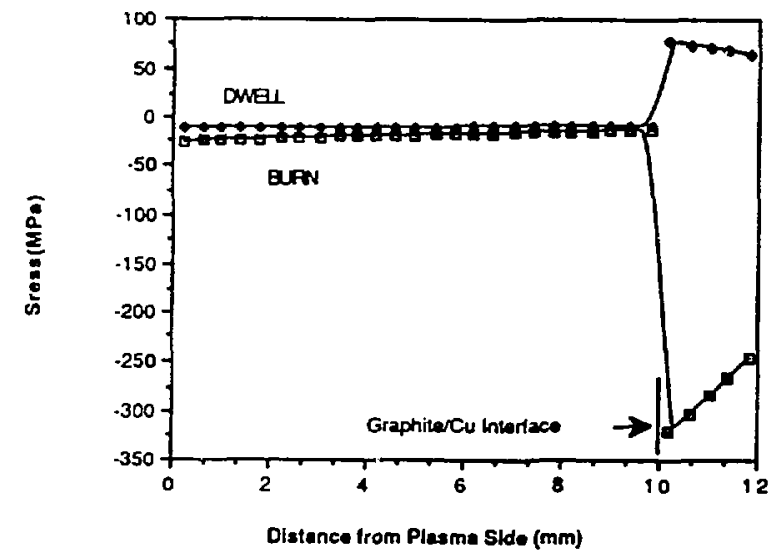

Fig. 11. Stress distribution through $\mathrm{C} / \mathrm{Cu} \mathrm{di}-$ vertor plate.

coefficient in graphite results in a relatively low stress level compared with the copper alloy. As radiation stress relaxation takes place, the low stress level is maintained in the graphite.

The copper stresses change from highly compressive to -0 during the burn, and they become highly tensile during dwell period, as shown in Fig. 12. The change from a mostly compressive stress cycle to a mostly tensile stress cycle as radiation stress relaxation occurs will result in an increase in the rate of fatigue damage accumulation. This situation is similar to the case of the first wall, described above. As shown in Fig. 13, the fatigue damage rate increases to about 60,000 cycles, and then continues at a constant rate until crack initiation is predicted at -12i), ijog cycles. Again, the ASME safety facto" of two in strain of 20 in cycles to ia $1, \ldots$ is incorporated into the calculations.

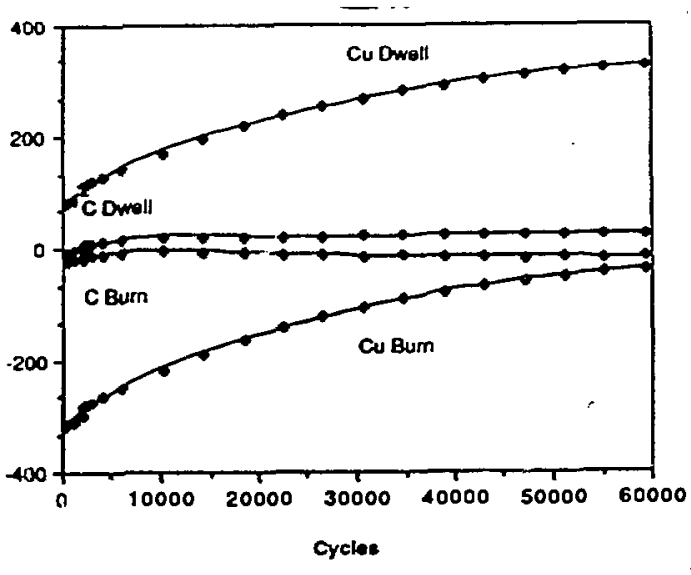

Eig. 12.Stress relaxation of $\mathrm{C} / \mathrm{Cu}$ divertor plate.

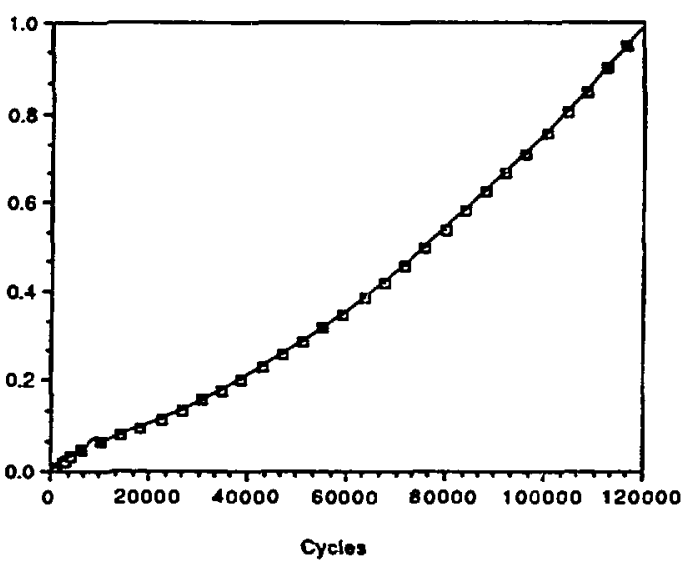

Fig. 13. Fatigue damage in $\mathrm{Cu}$ divertor plate.

\section{DISCUSSION AND CONCLUSIONS}

The results of the code calculations indicate the importance of radiation effects on performance. In the case of the first wall, the influence of radiation is most apparent for solution annealed stainless steel. It appears that even though the thermal strains can result in stresses beyond the initial yield stress, neutron irradiation will quickly harden the steel so that the stresses are fully in the elastic regime. After a time, the behavior of annealed material is predicted to be the same as coldworked material. The rice at which these changes occur are about 2 to 4 years of operation at $10 \%$ availability. Because this time represents a significant fraction of the ITER operating lifetime, radiaticn effects should be explicitly considered in any first wall design criteria, and they need to be included in any lifetime assessment.

The results of the divertor analysis illustrate the importance of considering both irradiation effects and surface erosion. In 
particular, the properties of graphite are expected to vary rapidly with neutron fluence. Initially, the reduction in thermal conductivity will cause a rapid increase in the temperatures. Only if rapid erosion accompanies the neutron radiation will the surface temperature be maintained at a low level. At higher fluences, degradation in the mechanical properties of graphite can be anticipated. The long term effect of mechanical property loss still needs to be investigated. The rain conclusion for the divertor is the sane as the first wall, however. Irradiation effects need to be explicitly considered in both the design and lifetime analyses.

The ITER desi/n team is considering the use of carbon-ci/rbon composites for the divertor plate berause of its enhanced thermal o shock resistance. Unfortunately, there are essentially no data on the irradiation effects for this class materials. If the degradation to the properties of the composites is similar to nuclear graphites, then the advantage of using composites may be small. It is criticaily important to develop an irradiation data base for composites to determine their applicability to ITER.

Another critical area for divertor plate design is the bond between the plasma side material and the heat sink. The bonding method (e.g. brazing) will have a significant influence on the residual stresses within the structure. During operation, the performance of the bond is, of course, crucial to the performance of the divertor plate. At this point, there is very little information available on bond properties or on the irradiation behavior.

Finally, the operating performance of plasma facing components will depend upon the specific component design and the stress constraints imposed by the design. The cases examined in this paper only illustrate the trends expected. A more thorough analys is is required to account for the presence of primary stresses (gravitational loads, coolant pressure, etc.) and actual geometry and stress constraints. There is also a need to assess crack growth beyond fatigue crack initiation, since in a high cycle environment, crack growth represent the most likely mode of failure.

\section{REFERENCES}

1. R.F. MATTAS, "Fusion Component Lifetime Analysis," ANL/FPP/TM-160, Argonne National Laboratory (1092).

2. F.L. SIMONS, "Tensile Property Correlation for 20\% Cold-Worked Type 316 Stainless Steel," J. Nucl. Mater.2 103, 815 (1981).
"Nuclear Systems Materials Handbook, Vol. 1, Deslgn Data," TID-26666.

4. W.M. STACEY et al., "US FED-INTOR Activity," USA EED-INTOR/82-1, Chapter VII, Impurity Control and First Wall Engineering (1982).

5. Y.S. TOULOUKIAN, ed., Thermophysical Properties of High Temperature Solid Materials, The MacMillian Company, New York (iyói).

6. "Materials Handbook for Fusion Energy Systems," DOE/TIC--10122.

7. G.B. ENGLE and B.T. KELLEY, J. Nucl. Mater., 122\&123, 122 (1984).

8. K.L. WILSON, ed., "The Utillty of Graphite and Carbon/Carbon Composites for Eusion Reactor Applications," Conf. No. 8706181, Sandia National Laboratories (1987).

9. F.W. WIEFEN and R.E. GOLD, ed., "Proceedings of Workshop on Copper and Copper Alloys for Fusion Beactor Applications," Conf-830466 (1984).

A. Thite (all capitals, centere!!)

B. Tille (if needed)

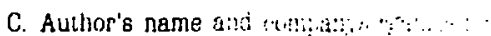

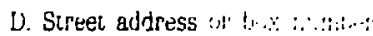

E. Cliy, state, : :

f. Teieqhorie ilutiss:

G. Pirst line of paire:

H. Page number 